\title{
Perceptions That Early Learning Teachers Have About Outdoor Play and Nature
}

\author{
Beverlie Dietze and Diane Kashin
}

\begin{abstract}
This study explored voices of early learning teachers engaged in discussions in an online outdoor play and nature pedagogy course. Three core questions were investigated that focused on early learning teachers' perceptions and practices of children's access to quality outdoor play and nature experiences. The results support previous research that indicated that teachers' perceptions, experiences, values, knowledge, and attitudes influence children's outdoor play experiences. The findings suggest the need to increase access to professional learning that contributes to early learning teachers enhancing their confidence, awareness, and intentional programming, which results in shifting attitudes to fully embrace outdoor play and pedagogy.
\end{abstract}

\section{Background}

The early childhood education profession across Canada is undergoing numerous changes and the landscape continues to evolve. New governmental policies and curriculum frameworks have changed the terrain. There are more opportunities for families to access diverse early childhood education programs and there are expanded professional learning experiences for early learning teachers (Dietze \& Kashin, 2016). At the same time, there is an increased awareness about the need for children to have extended access to outdoor play (Gomboc, 2016; Hyvonen, 2011). Childhood is undergoing overwhelming change, including the loss of access to outdoor play and the freedom to explore and discover without adult intervention. Childhood is increasingly becoming an indoor culture. These changes, combined with a new generation of early learning teachers entering the profession, many of whom have limited experiences in nature (Crim, Desjean-Perrotta, \& Mosley, 2008; Ernst \& Tornabene, 2012; Gustafsson, Szczepanski, Nelson, \& Gustafsson, 2012; Gustavsson \& Pramling, 2014), is adding to the relevance of the discussion that calls for more support for early learning teachers in their outdoor play practice. There appears to be consensus in the literature of the importance of early learning teachers having access to and in acquiring credentials and competencies that reflect current evidencebased practices (Douglass, Carter, Smith, \& Killins, 2015; Royer \& Moreau, 2016) reflective of outdoor play pedagogy.

Play has long been the foundation of early childhood education (Dietze \& Kashin, 2019a, 2019b; Leggett \& Newman, 2017; Torkar \& Rejc, 2017). Now, there appears to be a growing consensus across disciplines on the importance of outdoor play becoming more explicit in postsecondary early childhood education training programs and in professional learning programs. Early learning teachers benefit 
from understanding how outdoor play pedagogy provides a framework that can nurture children's desires to act upon their curiosity, to explore, experiment and in making discoveries about their ideas, the environment, and of themselves (Torkar \& Rejc, 2017; Little, Sandseter, \& Wyver, 2012).

Approximately $60 \%$ of children living in Canada (Sinha, 2014) attend child care centres. The outdoor play space, programming requirements, and duration of time recommended for children to have actual outdoor playtime vary from province to province and from one jurisdiction to another. Generally, governmental approval bodies examine the outdoor play space of early learning and child care centres for fall zones and safety, rather than for the play potential that could occur in the space (Cooper, 2015, Leggett \& Newman, 2017).

Despite research that clearly articulates how outdoor play has the potential to influence children's development, including contributing to fostering values, attitudes, skills, and behaviours towards themselves, others, and their environment, many early learning and child care programs are challenged to provide intriguing and stimulating outdoor environments (Frost \& Sutterby, 2017). This may be due in part to limited resources (Cooper, 2015; Leggett \& Newman, 2017; Wyver et al., 2009) and the lack of access and training available to early learning teachers that is specific to outdoor play pedagogy and programs. Online learning opportunities are gaining attention as an effective way to support early learning teachers in having access to professional development (Stone-MacDonald \& Douglass, 2015).

As a way to understand early learning teachers' perceptions about outdoor play and nature, it is important to listen to and hear their voices about their experiences, challenges, barriers, and aspirations for outdoor play programming. It is in this context that this paper presents results of a recent study of comments made by early learning teachers in online discussion boards found in an Internet-based outdoor play course. To the best of our knowledge, this online outdoor play course is the only one of its kind in Canada where early learning teachers collaboratively share their ideas, perspectives and articulate their recommendations for change to the view of advancing outdoor play pedagogy and practice.

\section{The Outdoor Play Course}

Designed for early learning teachers and emerging early learning teachers studying to practice in the early learning profession, a 36-hour open-access course was developed by two researchers/educators with extensive backgrounds in research and in facilitating professional learning related to outdoor play. The course consisted of 12 open-access modules that focused on an array of topics including why outdoor play is the hallmark for children's development, the adult's role in outdoor play and learning, designing outdoor play spaces, place-based education, nature pedagogy, and environmental sustainability. The asynchronous delivery model comprised various means of participant engagement in the modules, including the reviewing videos, PowerPoint slides, images, click-and-reveal features, and discussion forums. 
The intent of the course was to provide participants with outdoor play pedagogy, theory, and application strategies to support the achievement of praxis. Freire (1970) defined praxis as, "reflection and action directed at the structures to be transformed" (p. 126). Theory applied to practice could result in transformation of play and learning experiences for children. Children could have more time for outdoor play. Ideally, by transferring theory to practice, the quality and depth of the experience children have during outdoor play would also increase. Grounded in the premise that quality outdoor play experiences for children involves self-directed and hands-on experiences in and with nature, a concern for the authors was whether an online environment would lead to participant engagement and transference of theory to practice. Addressing this concern occurred from the analysis of the answers given by the participants to three core questions. The first question was, "Is the nature-based early childhood education movement and forest and nature movement influencing your program/practice?" The second question explored was, "What is your role in advancing the outdoor play movement?" The third question was, "What are the barriers and challenges of the outdoor play portion of your program?"

\section{Methodology}

\section{Research Methods and Participants}

This qualitative study was completed as part of a research project funded by the Lawson Foundation and conducted in accordance with the ethical standards set out by the Government of Canada's Tri-Council Policy for the Ethical Conduct for Research Involving Humans. The research was approved by a Research Ethics Board at a postsecondary institution. All participants provided their informed consent. As part of the research study, participants were required to complete a pre-course and post-course survey. The pre-survey provided demographics of participants including gender, age range, educational background, and work experience. As a way to maintain anonymity, the researchers only had access to the tag name that each participant used to sign into the course.

Data was collected from the examination of three questions that were embedded in the discussion forums of the modules. While some questions generated more discussion than others, all responses provided the researchers with insight into the perspectives that participants have on specific aspects of children and outdoor play.

\section{Heuristic and Narrative Inquiry}

This qualitative research was influenced by Moustakas's (1990) heuristic, narrative inquiry process. The heuristic inquiry paradigm explicitly encourages researchers to acknowledge the importance of the involvement and passion of the voices of participants (Hiles, 2001). Narrative inquiry is grounded on the premise that we come to understand and give meaning through story (Trahar, 2009). The researchers gained new insight into the state of outdoor play and nature play by listening to the voices of the early learning teachers through the stories that they shared and the exchanges that occurred in the course discussion forums. 
Examining the voices of the participants provided researchers with a deeper understanding of the early learning teachers' perspectives, challenges, and their recommendations for advancing children's outdoor play experiences. As inherent in the heuristic methodology, the process contributed to the researchers making discoveries and engaging in the exploration and interpretation of participants' experiences. Building on this exploration metaphor, the study subscribes to the interpretive paradigm articulated by Spradley (1980). He compares interpretive researchers to explorers who are trying to map a wilderness. In his analogy, he suggested that the main point of the activity is to describe the findings.

Considering the narratives posted in the forums allowed the researchers to gain an in-depth understanding of the particulars of the participants' points of view. The articulation of the knowledge acquired serves to offer the reader who has an interest in expanding the quality of children's outdoor play experiences with insight into the current thoughts and perspective of early learning teachers. It helps readers to think about what possible strategies for advancing the quality of children's outdoor play experience can be derived from these perspectives.

\section{Analyzing the Data}

The researchers examined the comments posted by the participants for each question. Using a constant comparison method, common key words and themes were sought within the posts. This led to the examination of the data to determine what variables were present, recognizing that the specific backgrounds and experiences of participants were unknown. With this constant comparison strategy, recurring patterns in the posts surfaced and themes emerged. At that point, the researchers shared their thoughts and questions with each other to determine the discoveries that each researcher had made about the themes and perspectives. They also examined the comments that correlated with the literature on outdoor play and pedagogy, preservice training, and professional learning.

\section{Findings}

The research questions were intended to invite participants to reflect upon current practices and perspectives related to outdoor play. The questions generated a range of responses. The intent of the initial exploration examined if the nature-based and forest and nature movement that appears to be building momentum across Canada is influencing the outdoor play practice of the participants in this study. The nature-based and forest and nature movement principles include adults advocating for and promoting outdoor play that supports children in acting upon their inquiries, experimentation and daily play in the same space/land for long periods of time, and in having new spaces to explore (Dietze \& Kashin, 2019a). The first question that participants responded to was, "Is the nature-based early childhood education movement and forest and nature movement influencing your program/practice?"

Two hundred and seven responses were examined for question one and summarized in Figure 1. Of the total number of responses, $61 \%$ of the respondents identified that to this point the movements were not influencing either their personal practice, the employment setting, or their work with early learning students or professionals in the profession. A common theme expressed among those 
participants was that their childhood experiences were much more of an influence in their practice than this movement. They suggested that as the child, their own exposure to outdoor play was as impactful. Others indicated that their place of employment and the attitudes of fellow teachers determined how outdoor play was positioned within their programs. Another prominent theme that emerged was that participants associated the lack of outdoor play space and materials as being a core contributor to early learning teachers not wanting to be outdoors.

Just over $10 \%$ of participants identified that the movements and the related research gave them tools that they could use to support families in understanding why outdoor play is important to children's development. Twenty-five percent identified that this course had made them aware of the nature-based and forest and nature movements. One of these participants suggested that it was not necessarily the movement which influences, but rather the need for children to be free, active, and able to enjoy nature, as it was meant to be!

I had a home daycare for 4 years, until I became director of a centre, of 47 children. When I was on my own, playing outdoors was important. However, I realized that the teachers who I now supervise do not value the same type of play as I do, which I find very discouraging. We need to be models and leaders, we need to show children what the outdoor life has to offer. I'm into this Outdoor Play Revolution!

Three participants identified their roles as early learning consultants. They indicated that they were seeing a large number of centres intentionally expand their outdoor playtime and experiences. In the words of one of these consultants, the forest and nature school movement

has become a popular topic of conversation with the many schools that I work with. Teachers are reaching out for help on how to adapt their practice and utilize outdoor spaces more regularly and more intentionally. Many teachers are concerned with policy, litigation, parent concerns, and logistics. I find that many willing teachers are reluctant to take play and learning outdoors because there are hurdles in place that are a legacy from the decline in outdoor play.

Similarly, more than $80 \%$ of the respondents identified that the more they engaged with children outdoors, the more benefits they were seeing for the children and for themselves such as happier children, more pro-social engagement among children, and a reduction in the amount of adult intervention required during the play.

Two participants identified themselves as college faculty teaching in early childhood education programs. They indicated that although they were including more outdoor play curriculum in their programs, they were not seeing a significant increase in outdoor play or in the quality of the outdoor play programming in the field. Five participants enrolled in college or university courses at the time of taking the outdoor play course indicated that there had not been any curriculum presented associated with outdoor play or nature play.

Seventy-five participants did not explicitly answer whether the movement was or was not influencing their practice. However, more than $50 \%$ of the participants suggested that challenges of weather, the demands that families make on early learning programs to focus on academic programming, the fear 
of children becoming ill from the weather, and the lack of ministry policies negatively influenced their desire to increase outdoor play.

\begin{tabular}{|l|c|}
\hline More outdoor play has benefits to children. & $80 \%$ \\
\hline The movements are not influencing practice. & $61 \%$ \\
\hline Challenges and barriers negatively influencing. & $50 \%$ \\
\hline Did not specifically answer the question. & $36 \%$ \\
\hline $\begin{array}{l}\text { This course has provided awareness of the } \\
\text { movements. }\end{array}$ & $25 \%$ \\
\hline $\begin{array}{l}\text { The movements provide tools and research to } \\
\text { support practice. }\end{array}$ & $10 \%$ \\
\hline $\begin{array}{l}\text { Consultants who noticed awareness of the } \\
\text { movements amongst centres. }\end{array}$ & $1.5 \%$ \\
\hline $\begin{array}{l}\text { Faculty seeing more outdoor play curriculum, but } \\
\text { not significant change in the field. }\end{array}$ \\
\hline
\end{tabular}

Fig. 1: Responses to Question One - Is the nature-based early childhood education movement and forest and nature movement influencing your program/practice?

As noted by Ross, Nicol, and Higgins (2007), teachers' in-depth perspectives about their role in changing practice, particularly in the case of advancing outdoor play, is important. As part of their role, Royer and Moreau (2016) suggested that the psychological well-being of early learning teachers, such as their feeling of competency and desire for involvement, influences practice. This reinforces the importance of emerging and early learning teachers having exposure to outdoor play pedagogy both in their formal schooling and as part of their professional learning options.

In response to the second question, "What is your role in advancing the outdoor play movement?" 131 responses were examined, which revealed key themes that provide insight into areas requiring attention, if we wish to advance outdoor play pedagogy with and for children. These are rounded off and summarized in Figure 2. More than $90 \%$ of respondents indicated the need to bring more visibility to the importance of outdoor play. They suggested this might include providing families with education, experiences, and examples of how outdoor play supports children's learning. More than half of the respondents identified the need to support families in understanding the benefits to children in having access to and opportunities for daily outdoor play. Further, these respondents advocated for them to have information that could easily be provided to families on topics such as the importance of children having the freedom to play and get dirty, and the differences between healthy, risky play, and play with hazards to share with families.

Fifteen participants identified that with an increase in immigrant and new Canadian families in their centres, there was a need to have appropriate resources in place to facilitate supporting those families in understanding the relationship of outdoor play to healthy development and in reassuring them that there were safety measures in place. Three respondents gave examples of refugee families who expressed their past concerns about children being outdoors because of issues such as land mines. Other examples given included supporting families from warmer countries in understanding that children do not get sick from cold weather or rain. Others suggested that new families to Canada wanted their children to focus on learning English, so they were ready for school. These families assumed children having structured 
experiences indoors with teacher-directed instruction would achieve this, rather than occurring during outdoor play.

The next most significant theme participants identified revolved around their personal practices that needed rethinking in order to advance children's outdoor play. Fifty-six percent of the respondents suggested their need to increase their observation skills and frequency of observations of children during outdoor play. They suggested this would contribute to them understanding children's interests and experiences. The comments suggested that the participants viewed their role in conducting observations as an advocacy because of how the results could influence the types of experiences and materials offered to children. Just over $88 \%$ of the respondents indicated that they now view their lack of planning for and knowledge about outdoor play as a professional challenge resulting in missed opportunities for children. Some suggested because their past view of outdoor play was as free play that did not require planning, a new revelation occurred during the course that had them thinking about how planning and provocations would change children's outdoor play experiences. As participants discussed reframing their practice, more than half of the respondents indicated the importance of increasing more intentional programming. This would require changing the materials in the outdoor environment, beginning with replacing the plastic toys with more natural materials. As well, observing children in their play would inform them how to increase the possibilities for learning. More insight would be gained about placebased learning and materials that could be used to scaffold children's experiences, which would provide opportunities for co-construction of learning among children and teachers.

Fifteen percent of the participants documented the need for them to become stronger advocates for children to have the time, space, and materials to follow their curiosity and interests, rather than the strict schedules used to manage the day-to-day routines. One respondent suggested the first step in advocating for outdoor play would be to change adult and children's attitudes and opportunities for outdoor play. She noted this would fuel children's curiosity and influence both children and adults wanting to be outdoors. More than $60 \%$ of participants expressed their need to have more opportunities to learn about how to become a better role model and advocate for outdoor play. Some suggested that a starting point might be to work toward refocusing negative attitudes that their fellow colleagues have about outdoor play so that as a team they could collectively advocate to change children's outdoor play experiences. As one responded articulated,

something that can interfere with outdoor play is the attitude of the educator towards outdoor play, scheduling, or additional expectations. I believe that as a team these things can be worked out to ensure that children have ample time to play outdoors.

Others suggested that to make significant changes to their current outdoor play practice, that they needed support, guidance, and resources from their supervisors.

One hundred and twenty-one respondents indicated that they personally needed to learn more about the theory and application of outdoor and nature play pedagogy. Some suggested this was missing both in their formal training programs and in current professional learning options. Many identified the need for more information about what types of play are acceptable during the outdoor play portion of the program. 
For example, 118 participants made mention of not knowing the difference between risky play and hazard until engaging in the modules. Others suggested if early learning teachers do not have the background to effectively program for the outdoor environment, they might not have the comfort and confidence to support children in embracing and engaging in a variety of experiences, including risky play. This affects the depth and breadth of the experiences extended to children. Others discussed their lack of comfort in supporting children in play that involved more active, adventurous experiences. They felt unprepared to be able to defend the play, especially in the event if children get hurt (Brussoni, Ishikawa, Brunelle, \& Herrington, 2017). Some questioned how much support they would receive from their administration and from families if children had an accident during outdoor play.

More than $70 \%$ of the participants identified that they had not been familiar with the process of conducting a risk-benefit assessment of potential experiences until this course. Such gaps in knowledge and practice reinforce the benefits of early learning teachers having access to continuous professional learning (Carroll-Lind, Smorti, Ord, \& Robinson, 2016).

\begin{tabular}{|l|c|}
\hline $\begin{array}{l}\text { There is a need to learn more about the theory and } \\
\text { application of outdoor and nature play pedagogy. }\end{array}$ & $91.5 \%$ \\
\hline $\begin{array}{l}\text { There is a need to bring more visibility to the } \\
\text { importance of outdoor play. }\end{array}$ & $90 \%$ \\
\hline $\begin{array}{l}\text { There is a need for professional development as } \\
\text { prior to this course the difference between risky } \\
\text { play and hazard was unknown. }\end{array}$ & $90 \%$ \\
\hline $\begin{array}{l}\text { The lack of planning for and knowledge about } \\
\text { outdoor play as a professional challenge resulting } \\
\text { in missed opportunities for children. }\end{array}$ & $88.5 \%$ \\
\hline $\begin{array}{l}\text { Until the course, lack of awareness of risk-benefit } \\
\text { assessments. }\end{array}$ & $70.5 \%$ \\
\hline $\begin{array}{l}\text { There is a need to have more opportunities to learn } \\
\text { about how to become a better role model and } \\
\text { advocate for outdoor play. }\end{array}$ & $60.5 \%$ \\
\hline $\begin{array}{l}\text { There is a need to increase observation skills and } \\
\text { frequency of observations of children during } \\
\text { outdoor play. }\end{array}$ & $56 \%$ \\
\hline $\begin{array}{l}\text { There is a need to support families in understanding } \\
\text { the benefits of daily outdoor play and having more } \\
\text { information would be helpful. }\end{array}$ & $52 \%$ \\
\hline $\begin{array}{l}\text { There is a need to become stronger advocates for } \\
\text { children to have the time, space, and materials to } \\
\text { follow their curiosity and interests, rather than the } \\
\text { strict schedules. }\end{array}$ & $15 \%$ \\
\hline $\begin{array}{l}\text { With increase in new Canadians there is a need to } \\
\text { have appropriate resources to support families in } \\
\text { understanding the relationship of outdoor play to } \\
\text { healthy development. }\end{array}$ & $11.5 \%$ \\
\hline
\end{tabular}

Fig. 2: Responses to Question Two - What is your role in advancing the outdoor play movement? 
Many factors influence the quality of outdoor play and nature environments and children's experiences. Some common factors affecting early learning quality include budgetary concerns, staff/child ratios, environmental factors, leadership, and the values that families, early learning teachers, and the programs embrace (Leggett \& Newman, 2017; Dietze \& Kashin, 2016; Douglass et al., 2015). Participants in this study added additional considerations as they relate specifically to outdoor play environments and nature play, such as the administrator's role, the need for continuous professional learning and collaboration amongst colleagues.

The final question examined 189 responses related to the barriers and challenges that were influencing their program. The participants were asked to respond to, "What are some of the barriers and challenges of the outdoor play portion of your program?"

Several themes evolved within this discussion forum. One of the most significant barriers cited by more than $90 \%$ of the participants was around the beliefs and lived experiences with the provincial licensing guidelines and the liabilities if children get hurt. Some participants suggested that they were required to remove climbers, water tables, and barrels when government regulations and licensing requirements changed on what was deemed safe and acceptable for licensing. As well, in some instances licensing officers required the natural places for puddles to form in the space to be filled in with products such as mulch. These changes resulted in children's outdoor play spaces being sterile, flat ground environments, and having limited materials (Leggett \& Newman, 2017). Another barrier cited frequently was the attitudes of families as it relates to outdoor play. Eighty-eight percent of the participants suggested that they have been witness to families complaining about children being outdoors in the cold or other unfavourable weather conditions due to potential illness. Another common complaint cited was that families expressed concerns if children were spending too much time outdoors because outdoor play would not provide children with the expected academic skills needed to enter kindergarten or grade one. Moreover, participants suggested that families did not want children being dirty at pick-up time.

As outlined earlier, another barrier that was prevalent in the responses related to the attitudes of coworkers. More than $66 \%$ of respondents indicated that there was inconsistency in children having access to outdoor play, the types of play that children were allowed to engage in, the number of children that could be in particular play spaces, and the duration allocated for outdoor play. They suggested the attitudes of coworkers strongly influenced these inconsistencies. A small percentage of participants suggested that although their space and geographic locations could be viewed as a barrier or challenge in offering outdoor play, with the right teacher attitude and support from administration, quality outdoor play experiences could be accomplished. 


\begin{tabular}{|l|c|}
\hline $\begin{array}{l}\text { A significant barrier cited was licensing guidelines } \\
\text { and the liabilities if children get hurt. }\end{array}$ & $90 \%$ \\
\hline $\begin{array}{l}\text { Families complaining about children being } \\
\text { outdoors in the cold or other unfavourable weather } \\
\text { conditions due to potential illness was included as } \\
\text { a barrier. }\end{array}$ & $88 \%$ \\
\hline $\begin{array}{l}\text { Attitudes of coworkers affected the consistency of } \\
\text { children's outdoor play experiences. }\end{array}$ & $66 \%$ \\
\hline $\begin{array}{l}\text { Even with less than ideal space, with the right } \\
\text { attitude and support quality outdoor play can } \\
\text { happen. }\end{array}$ & $2 \%$ \\
\hline
\end{tabular}

Fig. 3: Responses to Question Three - What are some of the barriers and challenges of the outdoor play portion of your program?

\section{Discussion}

In this study, we examined three core questions that early learning teachers discussed as part of a specialized course on outdoor play and pedagogy. This study provides insight into some of the current perspectives that early learning teachers, consultants, and faculty in college and university programs have on outdoor play in a Canadian context. Although in many Canadian jurisdictions there is a movement toward children having nature-based and forest experiences in their daily lives, this study shows that the tenets of these movements are not explicit in early childhood education training, job requirements, programming, or practice with children. Given the indoor migration of childhood, outdoor play should be implicit. To make this change, supporting an awareness is required.

A variety of aspects influence early learning philosophy, programming, and practice, including government policies, preservice education, access to professional development, and working conditions within centres (Hartz-Mandell \& Umaschi, 2016). These all contribute to the quality in early childhood education programs. It appears from this research that to change programming, practice, philosophy, or values, the effectiveness of the change depends on both internal factors such as staff attitudes, supervisor support, staff knowledge, desire to change practice, and families using the facility (Dietze \& Kashin, 2019a; Grimwood, Gordon, \& Stevens, 2018; Cooper, 2015). External factors that influence children's access to and opportunities for outdoor play include college and university training programs that early learning teachers complete, and the accessibility of specialized professional learning (Conners-Burrow, Patrick, Kyzer, \& McKelvey, 2017; Hartz-Mandell \& Umaschi, 2016). In addition, government policies as they relate to the time children spend outdoors, programming expectations, outdoor play environmental conditions, and the interpretations of policies and processes are major components that require further exploration (Leggett \& Newman, 2017; Cox, Hollingsworth, \& Buysse, 2015).

The majority of the respondents acknowledged two key areas requiring attention is providing families with information about how outdoor play, in all kinds of weather, and how it supports children's development. Family attitudes about outdoor play, based on early learning teachers' experiences, have considerable influence on programming, experiences, and attitudes of both children and early learning teachers in their practice and advocacy for outdoor play. Early learning teachers are in a unique 
position to influence family attitudes. The results of this study indicated a need for resources to support their role as advocates for outdoor play.

For many participants, the online course provided them with opportunities to gain new knowledge about outdoor play; for others, the experience seemed to identify and solidify areas of their practice that they could strengthen, such as observation and documentation. Staff education, preservice training, in-service professional learning, and staff confidence in planning and facilitating outdoor play experiences are cited in many studies as important factors in advancing new programming. Although participants identified limited information about the types of gaps in their knowledge about outdoor play pedagogy and nature play (Dietze \& Kashin, 2019a), it is reasonable to believe that this may be due in part to outdoor play pedagogy being new to their practice. Furthermore, positioning outdoor play pedagogy as an explicit type of programming is newer to the literature and is necessary (Dietze \& Kashin, 2019a, 2019b; Leggett \& Newman, 2017; Gustavsson \& Pramling, 2014). Participants expressed excitement about their new learning and the opportunities to bring it to practice. With external factors addressed and consistency amongst educators in beliefs and values about outdoor play, children will have increased access to outdoor play.

It is interesting to note that there was more emphasis placed on the importance of shifting staff attitudes about outdoor play than specific comments related to the outdoor play space, environment, and availability of materials. One reason for this may be that if staff have positive attitudes and are enthusiastic about outdoor play, then the environment will evolve to support children's outdoor play. This could also suggest that when staff embrace outdoor play and pedagogy, that new views on the perceptions of environmental constraints are developed. New views could lead to a greater understanding of the possibilities inherent in outdoor play environments and an enthusiastic desire to provide these for children.

\section{Conclusions}

If the outdoor play and nature movement is to transfer to early learning environments, there is a need for early learning students, teachers, and supervisors to have access to individual and team professional development that will support them in learning together and engaging in new practices that emphasize outdoor play pedagogy and nature play (Dietze \& Kashin, 2019a).

Teachers' perceptions, experiences, values, knowledge, and attitudes influence children's outdoor play experiences. This study explored how the lived experiences of early learning teachers affect their current practice. It suggests that new knowledge can contribute to reframing current practices that support them in developing new practices that foster outdoor play. With gaps identified and barriers addressed, there is a profound interest in expanding outdoor play. The teachers' voices draw attention to the perceived and real challenges that they experience. Their voices give insight into how early learning teachers can advocate for change in policies and practices that will support children in having access to and opportunities to engage in quality outdoor play experiences. 
This study reinforces the need for early learning students, early learning teachers, and administrators to have access to professional learning that deepens their understanding and practices of why children require consistent access to outdoor play spaces, experiences, and role models that embrace and cherish outdoor play. The critical question now is how to incorporate the voices of early learning teachers in fostering change that results in gaining new knowledge about outdoor play, increasing advocacy, and the quality of the outdoor play environments that ultimately support children in having opportunities for and access to quality outdoor play experiences.

\section{Summary}

It is evident there is a growing consensus on the importance of outdoor play becoming more explicit in postsecondary training programs and professional learning programs among early learning teachers. In order to do so, the findings from this research suggest increasing awareness of the benefits of outdoor play, improving the confidence of early learning and child care teachers, increasing intentional programs, and creating a shift in perceptions of and attitudes towards outdoor play.

\section{Recommendations}

Provide online learning and training opportunities. Many early learning programs are challenged to provide intriguing and stimulating outdoor environments partly due to limited resources and lack of access to outdoor play pedagogy and programming training available.

Increase awareness of the benefits of outdoor play. Educate and support families, coworkers, and government agencies in understanding the benefits of children having access to outdoor play daily by providing examples of how outdoor play benefits children's learning.

Improve confidence in early learning and childcare teachers. Early learning teachers may not have the background to effectively develop programs for the outdoor play environment (i.e., not understanding the difference between risky play and hazard). By providing access to professional learning, opportunities that support learning, and engaging in outdoor play practices, early learning teachers will develop comfort and confidence in embracing outdoor play and nature environments.

Increase intentional programming. Past practices viewed outdoor play as free play without planning; to rethink outdoor play practice would require early learning teachers to engage in intentional observations and in changing the materials in the outdoor play environment, starting with replacing plastic toys for more natural materials.

Create a shift in perceptions of and attitudes towards outdoor play. Collectively advocate for outdoor play with governments, families, and coworkers. With the right attitude and support from administrators, quality outdoor play experiences will be accomplished. 


\section{Acknowledgments and Grant Information}

The authors acknowledge that financial support for the research was provided by the Lawson Foundation. The contents of this article do not necessarily represent the policies or perspectives of the Lawson Foundation or are endorsed by the Lawson Foundation.

\section{References}

Brussoni, M., Ishikawa, T., Brunelle, S., \& Herrington, S. (2017). Landscapes for play: Effects of an intervention to promote nature-based risky play in early childhood centres. Journal of Environmental Psychology, 54, 139-150.

Carroll-Lind, J., Smorti, S., Ord, K., \& Robinson, L. (2016). Building pedagogical leadership knowledge in early childhood education. Australasian Journal of Early Childhood, 41(4), 28-35.

Conners-Burrow, N. A., Patrick, T., Kyzer, A., \& McKelvey, L. (2017). A preliminary evaluation of REACH: Training early childhood teachers to support children's social and emotional development. Early Childhood Education Journal, 45(2), 187-199.

Cooper, A. (2015). Nature and the outdoor learning environment: The forgotten resource in early childhood education. International Journal of Early Childhood Environmental Education, 3(1), 85-97.

Cox, M. E., Hollingsworth, H., \& Buysse, V. (2015). Exploring the professional development landscape: Summary from four states. Early Childhood Research Quarterly, 32, 116-126.

Crim, C., Desjean-Perrotta, B., \& Moseley, C. (2008). Partnerships gone WILD: Preparing teachers of young children to teach about the natural world. Childhood Education, 85(1), 6-12.

Dietze, B., \& Kashin, D. (2016). Empowering pedagogy for early childhood education. Pearson Education Canada.

Dietze, B., \& Kashin, D. (2019a). Outdoor and nature play in early childhood education. Pearson Education Canada.

Dietze, B., \& Kashin, D. (2019b). Playing and learning in early childhood education (2nd ed.). Pearson Education Canada.

Douglass, A., Carter, A., Smith, F., \& Killins, S. (2015). Training together: State policy and collective participation in early educator professional development. New England Journal of Public Policy, $27(1), 5,1-13$.

Ernst, J., \& Tornabene, L. (2012). Preservice early childhood educators' perceptions of outdoor settings as learning environments, Environmental Education Research, 18(5), 643. Retrieved from https://www.tandfonline.com/doi/abs/10.1080/13504622.2011.640749?.journalCode=ceer20.

Freire, P. (1970). Pedagogy of the oppressed. [Translated by Myra Bergman Ramos]. New York, NY: Seabury Press.

Gomboc, K. (2016). Back to nature: Exploring the potential for implementing the Norwegian idea of outdoor days in the Slovenian school system/V naravo: Iskanje moznosti implementacije norveske ideje ucenja izven ucilnice v slovenski solski sistem. Revija za Elementarno Izobrazevanje, 9(4), 123-138. 
Grimwood, B. S., Gordon, M., \& Stevens, Z. (2018). Cultivating nature connection: Instructor narratives of urban outdoor education. Journal of Experiential Education, 41(2), 204-219.

Gustafsson, P. E., Szczepanski, A., Nelson, N., \& Gustafsson, P. A. (2012). Effects of an outdoor education intervention on the mental health of schoolchildren. Journal of Adventure Education \& Outdoor Learning, 12(1), 63-79.

Gustavsson, L., \& Pramling, N. (2014). The educational nature of different ways teachers communicate with children about natural phenomena. International Journal of Early Years Education, 22(1), 59-72.

Hartz-Mandell, K., \& Umaschi, S. S. (2016). Classroom coaching for professional development in early care and education. The Brown University Child and Adolescent Behavior Letter, 32(4), 1-7.

Hiles, D. (2001). Heuristic Inquiry and Transpersonal Research. Paper prepared for CCPE, London, October 2001. Retrieved from http://www.psy.dmu.ac.uk/drhiles/Hlpaper.htm

Hyvonen, P. T. (2011). Play in the school context?: The perspectives of Finnish teachers. Australian Journal of Teacher Education (Online), 36(8), 49-67.

Leggett, N., \& Newman, L. (2017). Play: Challenging educators' beliefs about play in the indoor and outdoor environment. Australasian Journal of Early Childhood, 42(1), 24-32.

Little, H., Sandseter, E., \& Wyver, S. (2012). Early childhood teacher's beliefs about children's risky play in Australia and Norway. Sage Journals, 13(4), 300-316. Retrieved from http://journals.sagepub.com/doi/abs/10.2304/ciec.2012.13.4.300

Moustakas, C. (1990). Heuristic research: Design, methodology, and applications. Newbury Park, CA: Sage Publications.

Ross, H., Nicol, R., \& Higgins, P. (2007). Outdoor study of nature: Teachers' motivations and contexts. Edinburgh Research Explorer, 39(2), 160-172. Retrieved from

https://www.research.ed.ac.uk/portal/files/31169856/CHRISTIE_Outdoor_Learning_Provision_in_Scottis $\underline{\text { h_schools.pdf }}$

Royer, N., \& Moreau, C. (2016). A survey of Canadian early childhood educators' psychological wellbeing at work. Early Childhood Education Journal, 44(2), 135-146. Retrieved from https://www.deepdyve.com/lp/springer-journals/a-survey-of-canadian-early-childhood-educatorspsychological-wellbeing-YH9zMnjOBK

Sinha, M. (2014). Spotlight on Canadians: Results from the general social survey, child care in Canada. Stats Canada, (6). Retrieved from https://www150.statcan.gc.ca/n1/pub/89-652-x/89-652-x2014005$\underline{\text { eng.pdf }}$

Spradley, J. (1980). Participant observation. The George Washington University Institute for Ethnographic Research, 53(4), 260.

Stone-MacDonald, A., \& Douglass, A. (2015). Introducing online training in an early childhood professional development system: Lessons learned in one state. Early Childhood Education Journal, $43(3), 241-248$.

Torkar, G., \& Rejc, A. (2017). Children's play and physical activity in traditional and forest (natural) playgrounds. International Journal of Educational Methodology, 3(1), 25-30. 
Trahar, S. (2009, January). Beyond the story itself: Narrative inquiry and autoethnography in intercultural research in higher education. In Forum Qualitative Sozialforschung/Forum: Qualitative Social Research, 10(1).

Wyver, S., Tranter, P., Naughton, G., Little, H., Sandseter, E., \& Bundy, A. (2010). Ten ways to restrict children's freedom to play: The problem of surplus safety. Sage Journals, 11(3), 300-316. Retrieved from http://journals.sagepub.com/doi/abs/10.2304/ciec.2012.13.4.300

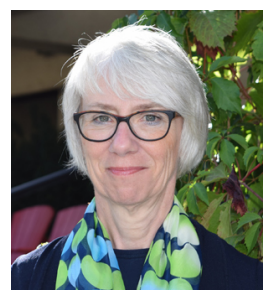

Beverlie Dietze is the Director of Learning and Applied Research at Okanagan College in Kelowna, BC. She engages in a variety of early childhood education related researcher projects that focus on outdoor play, professional learning models, and teaching and learning strategies. She has been a conference presenter and keynote speaker both nationally and internationally. She is the author and coauthor of several textbooks and peer-reviewed articles. Beverlie's educational background includes a Bachelor of Education, UNB, Masters of Adult Education, St. Francis Xavier University and a PhD, University of Toronto.

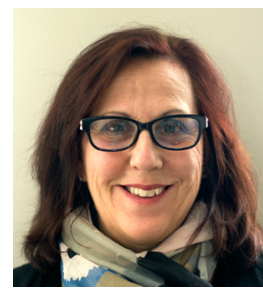

Diane Kashin, RECE, is a Professor in the Bachelor of Early Learning and Community Development degree program at Algonquin College, in Ottawa, Ontario. She is involved in research on outdoor play and nature pedagogy and has been a conference presenter and keynote speaker provincially, nationally, and internationally. She is the author of several textbooks and peer-reviewed articles. Her educational background includes an Honours B.A, York University, an early childhood education diploma, Seneca College, a Masters of Education, and Doctorate of Education, Ontario Institute for Studies in Education, University of Toronto. 